\title{
Prevalence of disrespect and abuse during facility based child birth and associated factors, Jimma University Medical Center, Southwest Ethiopia
}

\author{
Ahmed Siraj ${ }^{1}$, Woubishet Teka ${ }^{2}$ and Habtemu Hebo ${ }^{3 *}$ (i)
}

\begin{abstract}
Background: In countries where the proportion of births attended by skilled providers is low, maternal mortality is high. According to the 2016 EDHS report, the proportion of births attended by skilled providers was only 26\% and the maternal mortality ratio was 412 per 100,000 live-births. Disrespectful and abusive behavior of health workers and other facility staff experienced by women during facility-based childbirth is important, but the little-understood barrier of institutional delivery.

Objective: This study assessed the prevalence of disrespect and abuse experienced by mothers during facilitybased childbirth and associated factors.

Methods: A facility based cross-sectional study was undertaken from October to December 2016. Data were collected by face-to-face interview using a structured questionnaire from 290 mothers consecutively included in the study immediately prior to discharge from the hospital. Reports of disrespect and abuse during childbirth were measured using 23 performance indicators. Data were entered into EpiData and analyzed by SPSS; bivariate and multivariable binary logistic regression analyses were performed to identify factors associated with disrespect and abuse.

Result: Three-fourths (217,[74.8\%]) of participants were Muslim. Nearly half (142,[49\%]) had a primary level of education. Most (232,[80\%]) were housewives and 175(60.3\%) were from outside Jimma town. The prevalence of disrespect and abuse during childbirth was 91.7\% (266/290; 95\%Cl:0.879,0.946). The most common types of disrespect and abuse reported were culturally inappropriate care (218,[75.2\%]), failure to encourage the client to ask questions (220,[75.9\%]), the provider not introducing him/herself (232,[80.0\%]), failure to obtain consent/permission prior to any procedure $(185,[63.8 \%])$ and not using curtains/visual barriers to protect client (237,[81.7\%]). Being non-married [95\%Cl:(0.009,0.222) , zpara-II [95\%Cl:(0.093,0.862)] and being attended by female care provider [95\% $\mathrm{Cl}:(0.026,0.224)]$ were associated with the reduced chance of reporting disrespect and abuse. However, achieving $\geq$ secondary education [95\%Cl:(1.028,10. 272)] was associated with a higher chance of reporting disrespect and abuse.

Conclusion: The very high prevalence of abuse or disrespect during facility-based delivery shows a health system in crisis. A key implication of this finding is that efforts to increase facility-based delivery must address disrespect and abuse to ensure higher utilization by women. Making facility-based deliveries attended by female providers may reduce the problem.
\end{abstract}

Keywords: Disrespect, Abuse, Delivery, Childbirth, Facility-based, Ethiopia

\footnotetext{
* Correspondence: hjarso@rocketmail.com

${ }^{3}$ Department of Epidemiology, Public Health Faculty, Institute of Health,

Jimma University, Jimma, Ethiopia

Full list of author information is available at the end of the article
}

(c) The Author(s). 2019 Open Access This article is distributed under the terms of the Creative Commons Attribution 4.0 International License (http://creativecommons.org/licenses/by/4.0/), which permits unrestricted use, distribution, and reproduction in any medium, provided you give appropriate credit to the original author(s) and the source, provide a link to the Creative Commons license, and indicate if changes were made. The Creative Commons Public Domain Dedication waiver (http://creativecommons.org/publicdomain/zero/1.0/) applies to the data made available in this article, unless otherwise stated. 


\section{Plain English summary}

In countries where the proportion of births attended by skilled providers is low, maternal mortality is high. According to the 2016 Ethiopian Demographic and Health Surveillance report, the proportion of births attended by skilled providers was only $26 \%$ and the maternal mortality ratio was 412 per 100,000 live-births. Disrespectful and abusive behavior of health workers and other facility staff experienced by women during facility-based childbirth is important, but the little-understood barrier of institutional delivery. This study assessed the prevalence of disrespect and abuse experienced by mothers during facility-based childbirth and associated factors.

October to December 2016, consecutively included 290 mothers were interviewed immediately prior to discharge from the hospital. The result showed that nearly 92 out of 100 mothers were disrespected and abused during childbirth. Three-fourths of mothers did not receive culturally appropriate care and were not encouraged to ask questions. The provider did not introduce him/herself to four-fifths of mothers. The provider also did not request consent or permission prior to any procedure from nearly two-thirds of mothers. The provider did not use curtains or other visual barriers to protect client for more than four-fifths of mothers. Non-married mother, para-II or above mother and mother attended by female care provider had reduced chance of reporting disrespect and abuse. However, mother who attended at least secondary school had a higher chance of reporting disrespect and abuse.

In conclusion, the magnitude of disrespect and abuse during childbirth was very high in the study area indicating a health system in crisis. A key implication of this finding is that efforts to increase facility delivery must address disrespect and abuse to ensure higher utilization by women. Making facility-based deliveries attended by female providers may reduce the problem.

\section{Background}

In countries where the proportion of births attended by skilled providers is low, maternal mortality is high [1]. Reducing the global maternal mortality ratio to less than 70 per 100,000 live births by 2030 is the first target of Sustainable Development Goal (SDG) 3. The proportion of births attended by skilled health personnel is a critical progress indicator explicitly adopted for this target [2, 3]. Ethiopia had a plan to decrease the maternal mortality ratio (MMR) from 871 to 267 maternal deaths per 100,000 live births between 1990 and 2015 to achieve the millennium development goal (MDG) 5. A key indicator of this achievement was the proportion of births attended by skilled health personnel [4]. However, according to the 2016 Ethiopian Demographic and Health Surveillance (EDHS) report, maternal mortality ratio was 412 deaths per 100,000 live births [5]. Although the coverage of trained midwives increased to $72.7 \%$ in fiscal year $2015 / 16$ [6], the proportion of births attended by skilled providers was low (26\%) [5].

Lack of respect and courtesy from providers, perceived poor service quality, fear to expose the body to strangers, perceived costs of using health facility, and fear of being attended by male providers during birth are all known to contribute to low institutional delivery rates [7-15]. In Addis Ababa, the capital city of Ethiopia, though the proportion of births occurring in health institutions is much higher than the national Fig. (82.3\%), there are growing concerns about the respect and friendliness of safe delivery services [16].

Disrespectful and abusive behavior by health workers and other facility staff is important, but the little-understood component of the poor quality care experienced by women during childbirth in facilities. Non-abusive and respectful care at birth encompasses many points along a continuum spanning patient-centered and dignified care to overtly abusive and non-dignified maternal care. Maternal health experts and many stakeholders agree that disrespect and abuse (D\&A) during facility-based childbirth represent important causes of suffering for women and are important barriers to women choosing to access skilled care $[17,18]$. However, disrespect and abuse are often multi-factorial and may be perceived differently (or even normalized) depending on the specific setting.

According to Bowser and Hill's comprehensive review, the seven categories of disrespect and abuse during childbirth are physical abuse, non-dignified care, discrimination based on specific patient attributes, non-consented care, non-confidential care, abandonment of care and detention in facilities. However, it is known that manifestations of abuse and disrespect often fall into more than one category, and these categories are not intended to be mutually exclusive. Categories should be rather seen as overlapping and representing a continuum. Numerous factors (individual and community-level) may contribute to the experiences of disrespect and abuse. Lack of legal and ethical foundations to address D\&A, normalizing D\&A, lack of standards and accountability, lack of leadership commitment, and provider prejudice due to training and lack of resources are some among many factors $[17,18]$.

Disrespect and abuse of women during childbirth at health facilities have been qualitatively described, but there is little quantitative evidence on the prevalence of D\&A during facility-based maternity services delivered in low-resource settings. Few recent studies conducted in Kenya, Tanzania, Ethiopia, and Nigeria analyzed women's experiences during childbirth and estimated prevalence of disrespect and abuse that ranged from 20 to $98 \%$ [19-24]. Having a good understanding of the prevalence of D\&A and factors that influence it is, however, critical for developing interventions and encouraging clients' future facility utilization. This study, thus, 
aimed at quantitatively describing the level and types of disrespect and abuse women faced during facility-based childbirth.

\section{Methods}

\section{Study area and period}

The study was conducted in Jimma University Medical Centre (JUMC) from October to December 2016. JUMC is located in Jimma town, $352 \mathrm{Km}$ Southwest of Addis Ababa. JUMC is one of teaching medical centers in the country giving services to people living in Jimma zone and serving as a referral in Southwest Ethiopia. It is also serving as a clinical postgraduate specialty teaching hospital for Obstetrics and Gynecology, Internal Medicine, Pediatrics \& Child Health since 2005 and for Ophthalmology, Anesthesiology, and Surgery since 2007. Department of Obstetrics and Gynecology had 8 consultant Obstetricians \& Gynecologists and 33 residents (year I - IV), some midwives and nurses providing services. There were also final year undergraduate medicine students (Medical Interns), midwifery and nursing students providing services under supervision.

\section{Study design}

A quantitative cross-sectional study using intervieweradministered questionnaire was conducted to measure the prevalence of disrespect and abuse during facilitybased childbirth and associated factors.

\section{Study population}

All women who gave birth vaginally at JUMC during the study period and have been given consent were recruited for the study. Mothers who gave birth with cesarean section were excluded for two reasons; to rule out the effect of anesthesia, and to minimize the time lapse between childbirth and time of interview.

\section{Sample size determination and sampling technique}

A single population proportion formula was used to estimate the sample size with assumptions of $78.6 \%$ prevalence of any D\&A [21], 5\% margin of error, 95\% confidence level and 10\% non-response rate.

$$
\mathrm{n}=\frac{(\mathrm{Z} \alpha / 2) *(\mathrm{P} * \mathrm{Q})}{\mathrm{d} 2}=\frac{(1.96)^{2} *(0.786 * 0.214)}{(0.05) 2}=258
$$

Adding $10 \%$ for non-response, the final sample size became 284. Study participants were selected by convenient consecutive sampling technique until the required sample size was achieved.

\section{Variables}

Dependent variables: prevalence of disrespect and abuse (D\&A).
Independent variables: socio-demographic/economic characteristics [age, religion, ethnicity, marital status, educational status, address (Jimma town, Out of Jimma town), monthly income] and obstetric and service-related factors [parity, ANC use, history of institutional delivery, health provider (sex, number), length of stay, complication during delivery].

\section{Data collection and measurement}

Data were collected using structured questionnaire prepared after reviewing related literature. The questionnaire was translated into local languages (Amharic and Afan Oromo) and back-translated to English to ensure consistency of translation. A total of 39 questions (16 background and 23 D\&A questions) comprised the questionnaire and most questions were closed-ended (yes/no or multiple choice) (Table S1). The average time required to complete the questionnaire was $30 \mathrm{~min}$.

Data were collected by face-to-face interview (the data collectors asked the women the questions and they logged their responses) immediately prior to discharge from the health facility after childbirth. Data collection was delayed until the time of discharge from the hospital to reduce social desirability and recall biases. The soonest data collection was $6 \mathrm{~h}$ after childbirth. The interview was conducted in a quiet, private area of the unit with one woman and one interviewer. Four female nurses not involved in the women's care were recruited for data collection and trained for one day on how to use the data collection tool before embarking on data collection. Disrespect and abuse was measured by 23 verification criteria under major seven categories. The tool was adapted from the Maternal and Child Health Integrated Program (MCHIP) who developed it as part of its respectful maternity care toolkit [25].

\section{Data processing and analysis}

Data were entered into Epilnfo and analyzed using SPSS version 20 software. Descriptive statistics were computed. Adequacies of cells were checked in chisquare test for each independent variable. Bivariate binary logistic regression was performed for variables which had adequate cell count. A $p$-value $<0.05$ and clinical importance of variables were used to select candidate variables for multivariable logistic regression to avoid over-fitting of the model. Multicollinearity among independent variables was checked in a linear regression model. After multivariable logistic regression, a $p$-value $<0.05$ was used to declare statistical significance. Adjusted Odds Ratio (AOR) and 95\% CI were used to report the strength of association between outcome (any D\&A) and independent variables. 


\section{Data quality control}

Questionnaire translated to local language was back-translated to ensure consistency of translation. Data collectors were trained and data collection tool was pre-tested on 5\% of a sample before actual data collection. The supervisor checked filled questionnaires for accuracy and completeness on a daily basis. The supervisor replaced grossly incomplete filled questionnaires if the participants had left the hospital or returned to data collectors to fill the incomplete sections if the participants not yet left the hospital.

\section{Dissemination plan}

The finding of this study was submitted to Research and Graduate Studies Coordinating Office, Jimma University.

\section{Operational definition}

- Skilled providers or skilled health personnel or skilled birth attendants are health professionals who are educated and trained to national or international standards [2]. They are qualified to:

(i) Give evidence-based, human-rights-based, quality, socio-culturally acceptable and self-respectful care to women and newborns;

(ii) Help with physiological processes during labor and delivery to ensure a clean and positive childbirth experience;

(iii) Diagnose and treat or refer women and/or newborns with complications.

- For a specific category of abuse and disrespect with more than one verification criterion, a woman was labeled "abused and disrespected" in that category if she was abused and disrespected in at least one of the verification criteria during childbirth.

- If a mother was identified as disrespected and abused in at least one of the seven categories, she was considered "disrespected and abused".

\section{Results}

\section{Baseline characteristics}

Regarding socio-demographic characteristics, the majorities (220, [75.8\%]) were in the age group 20-29 years, 217 (74.8\%) were Muslim and 271 (93.4\%) were married. Nearly half (142, [49\%]) had a primary level of education. The majorities (232, [80\%]) were housewives and 175 (60.3\%) were from outside Jimma town. Nearly half (128, [44.1\%]) of the respondents were in the first two (lowest and second) households' monthly income quintiles. Concerning obstetric characteristics, more than half (150, [51.7\%]) were para one and almost all (285, [98.3\%]) had ANC for current pregnancy. The majorities (166, [57.2\%]) had no experience of institutional delivery. Regarding services, most (250, [86.2\%]) stayed in the hospital at most
$24 \mathrm{~h}$. More than half $(158,[54.5 \%])$ were attended by at most 2 professionals and most (237, [81.7\%]) were attended by male providers (Table 1 ).

\section{Prevalence of disrespect and abuse (D\&A)}

The overall prevalence (at least one form of disrespect and abuse) was 91.7\% (266/290; 95\%CI: 0.879, 0.946). The woman's right to information, informed consent, and choice/preference were not protected in 261 (90\%) of mothers. More than four-fifths $(255,[87.9 \%])$ of women were not protected from physical harm or ill-treatment during labor and delivery. Similarly, the woman's confidentiality and privacy were not protected in more than four-fifths of mothers (Fig. 1).

Most women (218, [75.2\%]) were not given the care in a culturally appropriate way by the care providers. Similarly, the care providers did not encourage the client to ask questions in most cases (220, [75.9\%]) and most mothers (232, [80.0\%]) reported that care provider didn't introduce him/ herself during childbirth. The provider also did not explain to the client what was being done and what to expect throughout labor and birth in more than half of the cases (150, [51.7\%]) and did not give her periodic updates on status and progress of labor in nearly half of the cases (143, [49.3\%]). In nearly two-thirds of clients (185, [63.8\%]), the provider did not obtain consent or permission prior to any procedure. Again, the provider did not use curtains or other visual barriers to protect the client in most cases (237, [81.7\%]) (Table 2).

\section{Factors associated with disrespect and abuse}

The association of maternal socio-demographic characteristics, reproductive factors and service-related factors with experience of disrespect and abuse during facility-based delivery was examined. The strength of the relationship was quantified using Odds Ratio (OR) and 95\% confidence interval. Accordingly, marital status, educational level, parity and sex of health provider had a statistically significant association with disrespect and abuse during facility-based childbirth. A respondent who was non-married (either single or widowed or divorced) was more than $95 \%$ lower likely [AOR: 0.046 ; $95 \% \mathrm{CI}:(0.009,0.222)$ to report disrespect and abuse than married. Clients with secondary education had more than three times higher [AOR: 3.25; 95\% CI: $(1.028,10.272)]$ chance to report disrespect and abuse compared to the respondent with primary or no formal education. A para two or above woman was nearly $72 \%$ lower likely [AOR: 0.283 ; 95\%CI: $(0.067,0.762)$ ] to report disrespect and abuse compared to para one woman. A mother whose delivery was attended by female care provider was more than 92\% lower likely [AOR: 0.076; 95\%CI: $(0.026,0.224)]$ to report disrespect and abuse compared to a mother whose delivery was attended by a male provider (Table 3 ). 
Table 1 Baseline characteristics of respondents, JUMC, Oct to Dec 2016

\begin{tabular}{|c|c|c|c|c|c|}
\hline \multicolumn{2}{|c|}{ Baseline characteristics } & \multirow{2}{*}{$\begin{array}{l}\text { Number (\%) } \\
24(8.3)\end{array}$} & \multicolumn{2}{|l|}{ Baseline characteristics } & \multirow{2}{*}{$\frac{\text { Number (\%) }}{150(51.7)}$} \\
\hline Age (years) & $15-19$ & & Parity & 1 & \\
\hline & $20-24$ & $112(38.6)$ & & $2-3$ & $107(36.9)$ \\
\hline & $25-29$ & $108(37.2)$ & & $>=4$ & $33(11.4)$ \\
\hline & $>=30$ & $46(15.9)$ & History of ANC use during current pregnancy & yes & $285(98.3)$ \\
\hline \multirow[t]{4}{*}{ Religion } & Muslim & $217(74.8)$ & & no & $5(1.7)$ \\
\hline & Orthodox & $55(19.0)$ & History of previous institutional birth & no & $166(57.2)$ \\
\hline & Protestant & $17(5.9)$ & & yes & $124(42.8)$ \\
\hline & Others & $1(0.3)$ & Length of hospital stay & $\leq 24 \mathrm{~h}$ & $250(86.2)$ \\
\hline \multirow[t]{2}{*}{ Marital status } & Married & $271(93.4)$ & & $>24 \mathrm{~h}$ & $40(13.8)$ \\
\hline & Others & $19(6.6)$ & Number of health professionals attended the mother & $1-2$ & $158(54.5)$ \\
\hline \multirow[t]{3}{*}{ Educational status } & No formal education & $67(23.1)$ & & $>2$ & $132(45.5)$ \\
\hline & Primary school & $142(49.0)$ & Sex of main health provider who attended a mother & Male & $237(81.7)$ \\
\hline & Secondary and above & $81(27.9)$ & & Female & $53(18.3)$ \\
\hline \multirow[t]{5}{*}{ Occupation } & Housewife & $232(80.0)$ & Faced birth complication/s during current labor & no & $232(80.0)$ \\
\hline & Employee & $39(13.4)$ & & yes & $58(20.0)$ \\
\hline & Merchant & $6(2.1)$ & Income quintiles & Lowest & $81(27.9)$ \\
\hline & Student & $5(1.7)$ & & Second & $47(16.2)$ \\
\hline & Others & $8(2.8)$ & & Middle & $73(25.2)$ \\
\hline \multirow[t]{2}{*}{ Residential address } & Outside Jimma & $175(60.3)$ & & Fourth & 39 (13.4) \\
\hline & Jimma town & 115 (39.7) & & Highest & $50(17.2)$ \\
\hline
\end{tabular}

\section{Discussion}

This study investigated the prevalence of disrespect and abuse faced by women during facility-based childbirth at Jimma University Medical Centre. Both verbal report (anecdote) and literature indicated that clients are often discriminated on the grounds of race, ethnicity, religion, age, socio-economic, and HIV status [17, 18]. This study also assessed the relationship between D\&A and socio-demographic/economic characteristic (age, religion, marital status, educational level, occupation,

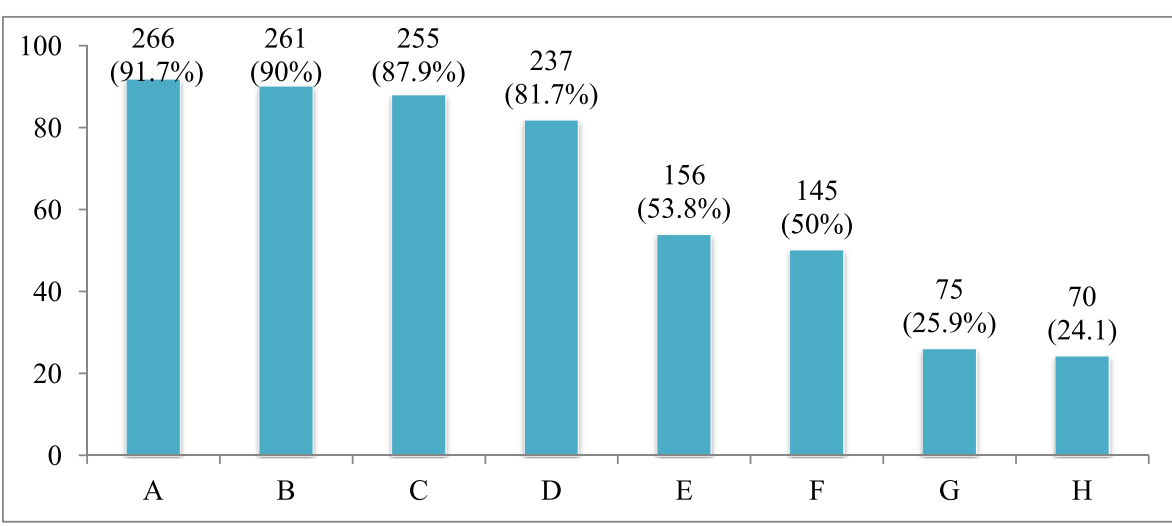

A The woman had at least one type of disrespect and abuse

B The woman's right to information, informed consent, and choice/preference was not protected

C The woman was not protected from physical harm or ill treatment

D The woman's confidentiality and privacy was not protected

E The woman was left without care/attention

$\mathrm{F}$ The woman was not treated with dignity and respect

G The woman was detained or confined against her will

$\begin{array}{lll}\mathrm{H} & \text { The woman did not receive equitable care, free of discrimination }\end{array}$

Fig. 1 Overall and category specific prevalence of disrespect and abuse, JUMC, Oct to Dec 2016 
Table 2 Distribution of types of disrespect and abuse reported by mothers during child birth, JUMC, Oct to Dec 2016

\begin{tabular}{|c|c|c|}
\hline Categories of disrespect and abuse & Types of disrespect and abuse $(n=290)$ & Number (\%) \\
\hline \multirow[t]{6}{*}{ Physical harm or ill-treatment } & mother did not cared for in a culturally appropriate way & $218(75.2)$ \\
\hline & mother denied food/fluid without medical indication & $108(37.2)$ \\
\hline & mother did not receive pain-relief as necessary & $103(35.5)$ \\
\hline & mother and newborn were separated without medical indication & $35(12.1)$ \\
\hline & mother was physically confined & $7(2.4)$ \\
\hline & physical force was used (e.g. slapping/hitting the mother) & $7(2.4)$ \\
\hline \multirow[t]{8}{*}{ Non-consented care } & service provider did not introduce him/herself to the mother & $232(80.0)$ \\
\hline & mother was not encouraged to ask questions & $220(75.9)$ \\
\hline & consent or permission prior to any procedure not obtained & $185(63.8)$ \\
\hline & $\begin{array}{l}\text { service provider did not explain what is being done and expected } \\
\text { outcome during labor and birth }\end{array}$ & $150(51.7)$ \\
\hline & periodic updates on status and progress of labor not given & $143(49.3)$ \\
\hline & $\begin{array}{l}\text { service provider did not answer questions promptly, politely and } \\
\text { truthfully }\end{array}$ & $129(44.5)$ \\
\hline & mother not allowed to move about during labor & $111(38.3)$ \\
\hline & mother not allowed to take position of choice during childbirth & $32(11.0)$ \\
\hline Non-confidential care & curtains or other visual barriers not used & $237(81.7)$ \\
\hline \multirow[t]{2}{*}{ Non-dignified care } & service provider did not speak politely & $95(32.8)$ \\
\hline & mother was insulted, intimidated, threaten, or coerced & $55(19.0)$ \\
\hline \multirow[t]{2}{*}{ Discrimination on specific grounds/ characteristics } & $\begin{array}{l}\text { mother shown disrespect based on religion or ethnicity or place of } \\
\text { residence, etc. }\end{array}$ & $47(16.2)$ \\
\hline & a language or language-level that mother cannot understand was used & $39(13.4)$ \\
\hline \multirow[t]{3}{*}{ Abandonment or denial of care } & provider did not arrive quickly when called & $105(36.2)$ \\
\hline & mother was not encouraged to call provider if needed & $85(29.3)$ \\
\hline & mother was left alone or unattended & $56(19.3)$ \\
\hline Detention or confinement in facilities & mother was delayed in health facility against her will & $75(25.9)$ \\
\hline Overall prevalence of disrespect and abuse & $\begin{array}{l}\text { mothers who faced disrespect and abuse in at least one of the } \\
\text { seven categories }\end{array}$ & $266(91.7)$ \\
\hline
\end{tabular}

household monthly income, residence), obstetric characteristics (parity, AN utilization current birth complication), length of stay in the hospital, number of health professionals who attended the mother, sex of main provider and whether someone other than concerned health provider had got access to see the mother during labor.

The overall prevalence of disrespect and abuse (91.7\%) observed in this study was higher than $81.8 \%$ prevalence reported by the study conducted in Addis Ababa, Ethiopia [21]. This could be because of the difference in settings where the culture of participants and composition of professionals caring for mothers differ. Though final year undergraduate medicine students also involved in facility-based childbirth attendance in both setups, the difference in how they were involved might have increased the magnitude of the problem in our setup. Three-fourths of respondents in our study were Muslims who don't want to be attended by male providers because of religious interest and culture of the surrounding community. Contrary to this, more than four-fifths of deliveries were attended by male providers. This contradiction might also have increased the report of disrespect and abuse in our setup.

Our finding was also more than four times higher than $19.5,20$ and $21 \%$ prevalence reported by studies done in Tanzania [20], Kenya [19] and Ethiopia [22] respectively. It was also more than six times higher than $15 \%$ prevalence reported by another study done in Tanzania [24]. Unlike our setup, participants might have normalized or under-reported disrespect and abuse during an immediate postpartum interview (courtesy bias) in both setups as evidenced by the increase of the prevalence to $70 \%$ during community follow up interview of Tanzanian study [24]. Kenyan and Tanzanian studies also included a significant proportion of mothers who gave birth by Cesarean section $[19,20]$. This might have led to the underestimation of prevalence as mothers are consented and better cared for (e.g. received anesthesia for pain) in such situation and thus, odds was reduced [19]. Providers have greater control over timing and setting of 
Table 3 Association between client baseline characteristics and reported disrespect and abuse (D\&A) during child birth, JUMC, Oct to Dec 2016

\begin{tabular}{|c|c|c|c|c|c|}
\hline & & \multicolumn{2}{|c|}{ Any D\&A } & \multirow[t]{2}{*}{ COR $(95 \% \mathrm{Cl})$} & \multirow[t]{2}{*}{ AOR $(95 \% \mathrm{Cl})$} \\
\hline & & Yes & $\mathrm{No}$ & & \\
\hline \multirow[t]{3}{*}{ Age } & $<25$ & 124 & 12 & $0.230(0.029,1.817)$ & \\
\hline & $25-29$ & 97 & 11 & $0.196(0.025,1.565)$ & \\
\hline & $\geq 30$ & 45 & 1 & 1 & \\
\hline \multirow[t]{2}{*}{ Religion } & Muslim & 201 & 8 & 1 & \\
\hline & Non Muslim & 65 & 16 & $0.162(0.066,0.395)$ & \\
\hline \multirow[t]{2}{*}{ Marital status } & Married & 253 & 18 & 1 & 1 \\
\hline & Others & 13 & 6 & $0.154(0.052,0.453)$ & $0.046(0.009,0.222)^{*}$ \\
\hline \multirow[t]{2}{*}{ Education } & $\begin{array}{l}\text { No formal education/ } \\
\text { primary school }\end{array}$ & 144 & 19 & 1 & 1 \\
\hline & Secondary and above & 122 & 5 & $3.219(1.168,8.877)$ & $3.25(1.028,10.272)^{*}$ \\
\hline \multirow[t]{2}{*}{ Occupation } & House wife & 215 & 17 & 1 & \\
\hline & Others & 51 & 7 & $0.576(0.213,1.736)$ & \\
\hline \multirow[t]{3}{*}{ Household monthly income (quintile) } & Lowest +2 nd & & & 1 & \\
\hline & Middle & & & $1.279(0.426,3.836)$ & \\
\hline & 4th + Highest & & & $0.952(0.367,2.471)$ & \\
\hline \multirow[t]{2}{*}{ Residence } & Jimma town & 102 & 13 & $0.526(0.227,1.219)$ & \\
\hline & Outside Jimma & 164 & 12 & 1 & \\
\hline \multirow[t]{2}{*}{ Parity (including current one) } & 1 & 146 & 8 & 1 & 1 \\
\hline & $>1$ & 120 & 16 & $0.411(0.170,0.993)$ & $0.283(0.093,0.862)^{*}$ \\
\hline \multirow[t]{2}{*}{ ANC utilization } & Yes & 262 & 23 & 1 & \\
\hline & No & 4 & 1 & $0.351(0.033,18.034)$ & \\
\hline \multirow[t]{2}{*}{ Length of stay in the hospital } & $\leq 24 \mathrm{~h}$ & 228 & 22 & 1 & \\
\hline & $>24 h$ & 38 & 2 & $1.833(0.421,16.692)$ & \\
\hline \multirow[t]{2}{*}{ Index birth complication } & Yes & 56 & 2 & $2.933(0.685,26.411)$ & \\
\hline & No & 210 & 22 & 1 & \\
\hline \multirow[t]{2}{*}{ Number of health professionals who attended the mother } & $1-2$ & 139 & 19 & 1 & \\
\hline & $>2$ & 127 & 5 & $3.472(1.259,9.572)$ & $3.011(0.838,10.823)$ \\
\hline \multirow[t]{2}{*}{ Sex of main health provider who attended mother } & Male & 228 & 9 & 1 & 1 \\
\hline & Female & 38 & 15 & $0.10(0.041,0.245)$ & $0.076(0.026,0.224)^{*}$ \\
\hline \multirow{2}{*}{$\begin{array}{l}\text { Someone other than concerned health provider had } \\
\text { got access to see you during labor }\end{array}$} & Yes & 61 & 3 & $2.083(0.601,7.220)$ & \\
\hline & No & 205 & 21 & 1 & \\
\hline
\end{tabular}

Caesarean section births and may perceive these cases as more serious, therefore behaving more professionally with the patient. A study conducted in Ethiopia was a health center based where client load was much lower and students were not involved in service delivery. Our finding was; however, lower than 98\% prevalence reported by the study undertaken in Nigeria [23].

Three-fourths of mothers were not given the care in a culturally appropriate way by the care provider which was more than eight times higher than the report of study from Addis Ababa, Ethiopia [21]. In more than three-fourths of the cases, the care provider did not encourage the client to ask questions and didn't introduce him/herself during childbirth similar to the report of studies conducted in Ethiopia [21, 22]. The provider did not explain to the client what to be done and what to expect throughout labor and birth and did not give periodic updates on the status and progress of labor in half of the cases. This is higher than the finding of the study undertaken in Addis Ababa, Ethiopia [21]. In two-thirds of clients, the provider did not obtain consent or permission prior to any procedure similar to the report of a health center based study conducted in Ethiopia [22] and Nigeria [23] but, higher than the report of a study done in Addis Ababa, Ethiopia [21] and Tanzania [20, 24]. The provider did 
not use curtains or other visual barriers to protect the client in four-fifths of the cases which was higher than the report of studies from Ethiopia [21, 22] and Tanzania [24].

In general, this figure indicates a worrisome picture of the quality of care during labor and delivery in the study facility. This is because, in many urban areas of resource-limited countries, improved access to services (especially in hospitals) has led to an increase in women seeking facility-based care during childbirth. As a result, many urban hospitals including our study facility had high patient flow and faced significant resource and staff shortages which are likely to be one of the key drivers of disrespect and abuse.

Women who attended secondary education or greater were more likely to report D\&A similar to the finding of Tanzanian study [20]. This is likely due to a combination of higher expectations of care quality and greater empowerment to report abuse. Those with experienced births (para two or above) were less likely to report D\&A similar to the finding of Tanzanian study [20,22]. This may indicate quicker and easier deliveries and/or greater resistance to or normalization of abusive remarks or behavior. It may also reflect anxiety about the birth experience as well as a greater need for care of those with first birth.

Previous studies have reported that married women were less likely to have experienced disrespect than unmarried women may be because of negative attitude among medical staff towards unmarried pregnant women [20]. However, we found that married women were more likely to have experienced disrespect than unmarried women may be because of more expectation of respectful care by this group.

Unlike previous studies, stay in the facility for delivery [20] and childbirth complications $[19,22]$ were not found associated with reporting D\&A. However, a woman whose delivery was attended by female healthcare provider was less likely to report D\&A. This could because of religious and cultural preference. In the current study, three-fourths of participants were Muslims and most were housewives which could be the reason for preferring female professionals.

\section{Limitations}

This study had some limitations. Disrespect and abuse is a complex concept to measure. Our assessment was based on self-report rather than objectively measuring the frequency of disrespectful and abusive care in the facility. However, given that disrespect and abuse are determined by women's own view of what is disrespectful and abusive, we believe that a self-reported measure is appropriate. Some studies have complemented exit interviews with community interviews conducted four to 10 weeks post-delivery to compare reported D\&A [20, 24]; others complemented it with observation [24]. Unfortunately, the study budget did not allow us for this method approach. Our analysis also did not include details of provider and facility-level factors as contributors to disrespect and abuse and thus, future research should explore these. Although interviews were conducted at the time of hospital discharge, the fact that women were asked about their care in the place where they give birth and by staff employed by the hospital, albeit not part of their care provision, may still induce social desirability bias.

\section{Conclusion}

The finding that nine out of 10 women experienced abuse or disrespect during facility-based delivery shows a health system in crisis. Abuse during childbirth may have far-reaching consequences in future health care utilization. A key implication of this finding is that efforts to increase facility-based delivery must address disrespect and abuse to ensure higher utilization by women and to safeguard women's fundamental rights during facility delivery. Making facility-based deliveries attended by female providers may reduce the problem.

\section{Abbreviations}

ANC: Antenatal Care; MDG: Millennium Development Goal; MMR: Maternal mortality ratio; EDHS: Ethiopian Demographic and Health Surveillance; D\&A: Disrespect and abuse; JUMC: Jimma University Medical Centre

\section{Acknowledgements}

The authors would like to extend their gratitude to the women who generously shared their time and insights in this research. They are also thankful to sponsor, data collectors and supervisors.

\section{Funding}

None.

Availability of data and materials

The datasets used and/or analysed during the current study are available from the corresponding author on reasonable request.

\section{Authors' contributions}

Conceptualization: AS and WT; Methods: HH, AS and WT; Data curation: AS; Formal analysis: AS, $\mathrm{HH}$ and WT; Report writing: AS, HH and WT; Manuscript preparation: $\mathrm{HH}$. All authors read and approved the final version of the manuscript.

\section{Ethics approval and consent to participate}

A written approval letter was obtained from an institutional review board (IRB) of Institute of Health, Jimma University (JU), before starting any data collection. All participants were told about the study and verbal consent was obtained. For a participant below 18 years of age, verbal consent was obtained from husband or her mother or her father as approved by the ethics committee. Verbal assent was also obtained from the participant. Verbal consent was documented in the questionnaire by marking the box in front of the agreement statement. Participants were also told that they have the right to withdraw from the study at any time during data collection. Participants were given the chance to ask questions before participating in the study. Respect for the religion, culture, norm and opinion of the participant was the priority during data collection. Collected data were also kept confidential and only research team had access to it. 


\section{Competing interests}

The authors declare that they have no competing interests.

\section{Publisher's Note}

Springer Nature remains neutral with regard to jurisdictional claims in published maps and institutional affiliations.

\section{Author details}

${ }^{1}$ Shenen Gibe Hospital, Jimma, Ethiopia. ${ }^{2}$ Department of Gynecology \& Obstetrics, Medical Science Faculty, Institute of Health, Jimma University, Jimma, Ethiopia. ${ }^{3}$ Department of Epidemiology, Public Health Faculty, Institute of Health, Jimma University, Jimma, Ethiopia.

Received: 30 January 2019 Accepted: 6 May 2019

Published online: 27 May 2019

\section{References}

1. WHO, UNICEF, UNFPA, The World Bank Estimates. Trends in maternal mortality: 1990 to 2010. Geneva: WHO Press; 2012

2. World Health Organization. Definition of skilled health personnel providing care during childbirth: the 2018 joint statement by WHO, UNFPA, UNICEF, ICM, ICN, FIGO and IPA. 2018; Available at: https://apps.who.int/iris/ bitstream/handle/10665/272818/WHO-RHR-18.14-eng.pdf?ua=1

3. United Nations. Transforming Our World: The 2030 Agenda for Sustainable Development; Available at: sustainabledevelopment.un.org.

4. National Planning Commission and the, United Nations in Ethiopia. Millennium Development Goals Report 2014 Ethiopia: Assessment of Ethiopia's Progress towards the MDGs. Addis Ababa, Ethiopia; 2015 Oct.

5. Central Statistical Agency (CSA) [Ethiopia] and ICF. 2016. Ethiopia Demographic and Health Survey 2016. Addis Ababa, Ethiopia, and Rockville, Maryland, USA: CSA and ICF.

6. Federal Democratic Republic of Ethiopia. The 2017 voluntary National Reviews on SDGs of Ethiopia: government commitments, Nationa Ownership and PerformanceTrends. 2017.

7. Tayelgn A, Zegeye DT, Kebede Y. Mothers' satisfaction with referral hospital delivery service in Amhara region, Ethiopia. BMC Pregnancy Childbirth [Internet]. 2011 Oct 24;11(1):78. Available from: https://doi.org/10.1186/14712393-11-78

8. Yebyo $\mathrm{H}$, Alemayehu M, Kahsay A. Why do women deliver at home? Multilevel modeling of Ethiopian National Demographic and health survey data. PLoS One. 2015;10:e0124718.

9. Tebekaw Y, James Mashalla Y, Thupayagale-Tshweneagae G. Factors influencing Women's preferences for places to give birth in Addis Ababa, Ethiopia. Obstet Gynecol Int 2015;2015:439748.

10. Tarekegn SM, Lieberman LS, Giedraitis V. Determinants of maternal health service utilization in Ethiopia: analysis of the 2011 Ethiopian demographic and health survey. BMC Pregnancy Childbirth. 2014;14:161.

11. Sipsma H, Thompson J, Maurer L, Bradley E, Curry L. Preferences for home delivery in Ethiopia: provider perspectives. Glob Public Health. 2013:8:1014-26.

12. Mirkuzie $\mathrm{AH}$. Exploring inequities in skilled care at birth among migrant population in a metropolitan city Addis Ababa, Ethiopia; a qualitative study. Int J Equity Health 2014;13:110.

13. Jackson R, Tesfay FH, Gebrehiwot TG, Godefay H. Factors that hinder or enable maternal health strategies to reduce delays in rural and pastoralist areas in Ethiopia. Tropical Med Int Health. 2016;22(2):148-60.

14. Hailu $\mathrm{D}$, Berhe $\mathrm{H}$. Determinants of institutional childbirth service utilisation among women of childbearing age in urban and rural areas of Tsegedie district. Ethiopia Midwifery. 2014;30:1109-17.

15. Asseffa NA, Bukola F, Ayodele A. Determinants of use of health facility for childbirth in rural Hadiya zone, southern Ethiopia. BMC Pregnancy Childbirth. 2016;16:355

16. Asefa A, Teshome W, Mesele T, Letamo Y. Use of institutional delivery services in the southern nations, nationalities, and People's region, Ethiopia: a cross-sectional comparative mixed methods study. Lancet. [Internet]. 2013 Oct 20 [cited 2018 Oct 19];382:9. Available from: https:// www.thelancet.com/journals/lancet/article/PIIS0140-6736(13)62170-4/ abstract.

17. Bowser D, Hill K. Exploring evidence for disrespect and abuse in facilitybased childbirth: report of a landscape analysis. Harvard School of Public Health, University Research Co., LLC; 2010 Sep.
18. Browser, Hill. Exploring evidence for disrespect and abuse in facility-based childbirth: report of a landscape analysis [internet]. Maternal Health Task Force. 2014 [cited 2018 Oct 19]. Available from: https://cdn2.sph.harvard. edu/wp-content/uploads/sites/32/2014/05/Exploring-Evidence-RMC_ Bowser_rep_2010.pdf

19. Abuya T, Warren CE, Miller N, Njuki R, Ndwiga C, Maranga A, et al. Exploring the Prevalence of Disrespect and Abuse during Childbirth in Kenya. PLOS ONE [Internet]. 2015 [cited 2018 Oct 19];10(4):e0123606. Available from: https://doi.org/10.1371/journal.pone.0123606

20. Kruk ME, Kujawski S, Mbaruku G, Ramsey K, Moyo W, Freedman LP. Disrespectful and abusive treatment during facility delivery in Tanzania: a facility and community survey. Health Policy Plan. 2018;33:e26-33.

21. Asefa A, Bekele D. Status of respectful and non-abusive care during facilitybased childbirth in a hospital and health centers in Addis Ababa, Ethiopia. Reprod Health [Internet]. 2015 Apr 16:12(1):33. Available from: https://doi. org/10.1186/s12978-015-0024-9

22. Banks KP, Karim AM, Ratcliffe HL, Betemariam W, Langer A. Jeopardizing quality at the frontline of healthcare: prevalence and risk factors for disrespect and abuse during facility-based childbirth in Ethiopia. Health Policy Plan. 2018;33:317-27.

23. Okafor II, Ugwu EO, Obi SN. Disrespect and abuse during facility-based childbirth in a low-income country. Int J Gynecol Obstet. 2015;28:110-3.

24. Sando D, Abuya T, Asefa A, Banks KP, Freedman LP, Kujawski S, et al. Methods used in prevalence studies of disrespect and abuse during facility based childbirth: lessons learned. Reprod Health [Internet]. 2017 Oct 11; 14(1):127. Available from: https://doi.org/10.1186/s12978-017-0389-z.

25. MCHIP and UNAIDS. Respectful Maternity Care: Country Experiences. 2012 Nov. Available from: https://www.k4health.org/sites/default/files/ RMC\%20Survey\%20Report.pdf
Ready to submit your research? Choose BMC and benefit from:

- fast, convenient online submission

- thorough peer review by experienced researchers in your field

- rapid publication on acceptance

- support for research data, including large and complex data types

- gold Open Access which fosters wider collaboration and increased citations

- maximum visibility for your research: over $100 \mathrm{M}$ website views per year

At $\mathrm{BMC}$, research is always in progress.

Learn more biomedcentral.com/submissions 